\title{
Perforation risk in pediatric appendicitis: assessment and management
}

This article was published in the following Dove Press journal:

Pediatric Health, Medicine and Therapeutics

\author{
Erin C Howell' \\ Emily D Dubina' \\ Steven L Lee ${ }^{1,2}$ \\ 'Department of Surgery, Harbor- \\ UCLA Medical Center, Torrance, CA, \\ USA; ${ }^{2}$ Division of Pediatric Surgery, \\ UCLA Mattel Children's Hospital, Los \\ Angeles, CA, USA
}

\begin{abstract}
Perforated appendicitis, as defined by a visible hole in the appendix or an appendicolith free within the abdomen, carries significant morbidity in the pediatric population. Accurate diagnosis is challenging as there is no single symptom or sign that accurately predicts perforated appendicitis. Younger patients and those with increased duration of symptoms are at higher risk of perforated appendicitis. Elevated leukocytosis, bandemia, high C-reactive protein, hyponatremia, ultrasound, and CT are all useful tools in diagnosis. Distinguishing patients with perforation from those without is important given the influence of a perforation diagnosis on the management of the patient. Treatment for perforated appendicitis remains controversial as several options exist, each with its indications and merits, illustrating the complexity of this disease process. Patients may be managed non-operatively with antibiotics, with or without interval appendectomy. Patients may also undergo appendectomy early in the course of their index hospitalization. Factors known to predict failure of non-operative management include appendicolith, leukocytosis greater than 15,000 white blood cells per microliter, increased bands, and CT evidence of disease beyond the right lower quadrant. In this review, the indications and benefits of each treatment strategy will be discussed and an algorithm to guide treatment decisions will be proposed.
\end{abstract}

Keywords: pediatric, perforated appendicitis, diagnosis, management, interval appendectomy

\section{Statement of the problem Epidemiology}

Appendicitis is the most common disease process requiring urgent surgery in pediatric patients. ${ }^{1-8}$ It is one of the most common reasons for pediatric hospital admissions, responsible for $60,000-80,000$ admissions annually in the USA. ${ }^{2,9,10}$ It is estimated that the lifetime risk of developing appendicitis is $7 \%$ in girls and $9 \%$ in boys, ${ }^{9,11}$ with a lifetime risk of appendectomy of $23.1 \%$ for females and $12.0 \%$ for males. ${ }^{11}$

\section{Pathophysiology}

Appendicitis exists as a spectrum of disease from simple inflammation to perforation with local contamination to perforation with extensive contamination. The primary etiology is thought to be obstruction of the appendiceal lumen from a variety of factors including lymphoid hyperplasia, appendicolith, foreign body, parasites, or malignancy. ${ }^{5,9,12,13}$ The obstruction of the lumen leads to distension of the appendix as it continues to secrete mucus and bacteria proliferate. This distension continues, resulting in impairment of lymphatic and venous drainage from the appendix and
Correspondence: Steven L Lee

Division of Pediatric Surgery, UCLA

School of Medicine, 10833 Le Conte

Avenue CHS Building, MC709818 Los

Angeles, CA, 90095-9818, USA

$\mathrm{Tel}+\mathrm{I} 3102062429$

$\mathrm{Fax}+\mid 310206$ II20

Email stevenlee@mednet.ucla.edu 
ultimately limiting arterial supply as well. As the disease progresses, appendiceal tissue undergoes necrosis and then perforates. ${ }^{9}, 12$ Although the natural progression of disease results in perforation, not all patients follow this progression and some will resolve spontaneously., ${ }^{9,114}$

\section{Nomenclature}

While describing appendicitis as a disease spectrum, it is also often described with a multitude of classifications. ${ }^{15}$ Acute, uncomplicated, complicated, advanced, purulent, perforated, gangrenous, necrotic, contained perforation, free perforation, and peritonitis are mentioned throughout the literature. In a study where a diagnosis of appendicitis severity was made on photographs compared to objective criteria, surgeons displayed considerable variability in diagnosis and poor agreement on which patients were perforated. ${ }^{16}$ The lack of evidence to support each individual classification and abundance of terms likely results in a high degree of redundancy with multiple terms used to describe the same entity. ${ }^{15}$ Holcomb and St Peter proposed defining perforated appendicitis as a hole in the appendix or an appendicolith in the abdomen, resulting in the dichotomous classification of appendicitis as perforated or non-perforated. ${ }^{15} \mathrm{~A}$ common, objective definition is critical to allow for comparing outcomes across different centers. ${ }^{15,17}$ This definition was validated prospectively and found useful for identifying patients at risk for developing postoperative abscess. ${ }^{17}$ This is the definition for perforated appendicitis that will be used in this paper.

\section{Who is at risk?}

Pediatric perforated appendicitis rates are often quoted at $\sim 30 \%$ with a range from $20 \%$ to $74 \%$, but can be much higher for younger children. ${ }^{6,11,13,18-27}$ Younger children have less ability to articulate their symptoms, and a retrospective study found perforation rates nearly $100 \%$ in patients less than 1-year-old and $69 \%$ in 5-year-olds. ${ }^{24}$ Higher perforation rates have been linked to pre-hospital factors such as race, social class, and insurance status. ${ }^{19,20,27,28}$ Perforated appendicitis rates were found to be higher in $\mathrm{Asian}^{19}$ and black children ${ }^{19,27}$ compared to white children. Children without insurance and children with public insurance also had higher perforation rates compared to privately insured children. ${ }^{19,27,28}$ Frequently associated with barriers to health care access, a longer duration of symptoms has been associated with higher perforated appendicitis rates. ${ }^{5,10,20,21,24-26,29,30}$ Perforated appendicitis has also been associated with the presence of an appendicolith. ${ }^{5,20,31}$

\section{Morbidity of pediatric perforated appendicitis}

The presence of perforation plays an important role in in patient morbidity. ${ }^{5,15-19,22,24,25,29,30,32}$ Perforated appendicitis has been associated with elevated postsurgical complications. ${ }^{19,22,25,30}$ Ponsky et al noted the risk of developing an intra-abdominal abscess, wound infection, or postoperative ileus was $39 \%$ vs $8 \%$ in perforated vs non-perforated appendicitis. ${ }^{19}$ Other complications include the development of pelvic collections and higher rates of readmissions. ${ }^{25}$ Longer length of stay (LOS) has also been associated with perforated compared to non-perforated appendicitis. . $^{18,22,24,25}$

Part of the morbidity of perforated appendicitis stems from its difficulty to diagnose, resulting in delays to appropriate treatment. ${ }^{4}$ Treatment for acute and perforated appendicitis differ. 4,6,7,9,10,33 Management of perforated appendicitis is much more complex with a myriad of treatment options and multiple controversies surrounding various aspects of each option. ${ }^{6,15}$

\section{Diagnostic challenges}

As children do not often manifest the classic presentation of appendicitis, correctly diagnosing perforated appendicitis poses additional challenges. ${ }^{4,12,34}$ Misdiagnosis of appendicitis has been observed in 15\%-28\% of patients in the emergency department. ${ }^{34,35}$ Pediatric patients may present with atypical and nonspecific symptoms, ${ }^{5,9}$ and young children have difficulty vocalizing their symptoms. ${ }^{9}$ There is no single symptom or sign reliable in predicting perforation. ${ }^{25}$ Experienced pediatric surgeons showed higher aptitude at diagnosing appendicitis. ${ }^{5,21,36}$ They have been shown to distinguish nonappendicitis, acute appendicitis, and perforated appendicitis at $96.8 \%, 93.5 \%$, and $93.5 \%$ accuracy, respectively. ${ }^{5,21}$

\section{Patient history}

Younger patients are at increased risk of perforated appendicitis., ${ }^{9,20,24-26}$ This follows an inverse linear relationship with patients less than 1-year-old who have rates of perforated appendicitis as high as $100 \%,{ }^{24}$ children less than 5 years old $69 \%-74 \%,{ }^{20,24}$ and children over 8 years old $30 \%-40 \%{ }^{20}$ Although being less than 5 years old is commonly associated with higher perforation rates than slightly older children, ${ }^{10,20,24}$ other studies have noticed a significant difference in perforation rates when using other age cutoffs such as 9-year-olds. ${ }^{25}$

Consistently throughout the literature, a longer duration of symptoms has been associated with perforated appendicitis in both adults and children. ${ }^{5,10,21,24,26,29,30,37}$ This ranges from symptoms being present for 24 hours, ${ }^{10} 36$ hours, ${ }^{20,29}$ or greater 
than 48 hours. ${ }^{5,21,25}$ In an adult study, presence of symptoms greater than 36 hours showed significantly increased risk for perforation, and this risk was seen to steadily increase over 12-hour increments. ${ }^{29} \mathrm{Within}$ the pediatric literature, there is a general trend that the increased symptom duration means increased risk of perforation, but there is not a consensus on a time cutoff amongst studies when this risk of perforation is significantly higher. ${ }^{5,10,20,21,24-26,30}$

Signs and symptoms that present with perforated appendicitis vary between studies. Anorexia ${ }^{5}$ and emesis ${ }^{5,26}$ have been associated with perforated appendicitis, but these are nonspecific. Generalized pain, diffuse tenderness, and peritoneal signs are more commonly present in perforated appendicitis compared to acute appendicitis, ${ }^{5,21,24,25}$ but their presence does not definitively diagnose perforated appendicitis. Similarly, patients who are more febrile have a higher risk of perforated appendicitis, but the specific temperatures of "more febrile" vary between studies..$^{5,25,26,30}$

\section{Laboratory markers}

Laboratory markers such as leukocytosis, bandemia, $\mathrm{C}$-reactive protein (CRP), erythrocyte sedimentation rate (ESR), and hyponatremia can also aid in the diagnosis of perforated appendicitis. Leukocytosis is the most frequently cited laboratory marker associated with perforation. . $^{5,9,10,21,30,38}$ Some authors state the presence of leukocytosis is predictive, ${ }^{10,30,38}$ while others qualify that it should be markedly elevated to signify perforation. ${ }^{5,9,21}$ Bandemia ${ }^{5,26}$ and elevated ESR (greater than $25 \mathrm{~mm} / \mathrm{h}^{5,25}$ ) have also been shown to be predictive of perforated appendicitis.

CRP has been looked at as a sole predictor of perforation or in combination with leukocytosis. ${ }^{5,30,38}$ Gosain et al found both CRP and leukocytosis to be univariate predictors of perforated appendicitis, but only leukocytosis greater than 19,400 cells per microliter was a multivariate predictor of perforation. ${ }^{5}$ Although Siddique et al found leukocytosis a better predictor than CRP for acute appendicitis, the sensitivity for diagnosing both acute and perforated appendicitis increased when leukocytosis and CRP were combined. ${ }^{30}$ Beltrán et al found leukocytosis and CRP, either alone or in combination, useful in diagnosing acute appendicitis. ${ }^{38} \mathrm{Com}-$ bining the two results or utilizing them individually leads to poor sensitivity for diagnosing perforated appendicitis, but improved specificity. ${ }^{38}$

Hyponatremia has been observed as a strong independent predictor of complicated appendicitis in children. ${ }^{10}$ Pham et al found significantly higher rates $(P<0.01)$ of hyponatremia in complicated appendicitis $(63 \%$ vs $33 \%, P<0.01)$ compared to non-complicated appendicitis. After increased duration of symptoms, it was the second strongest predictor of complicated appendicitis (OR 3.1, 95\% CI 2.0-4.9, $P<0.01) .{ }^{10}$ Hyponatremia has been documented as predictor of perforated appendicitis in the adult population. ${ }^{39,40}$ The concept of hyponatremia as a predictor of disease severity is not unique to appendicitis. Hyponatremia has been well documented as a predictor of mortality in necrotizing soft tissue infections ${ }^{41,42}$ and a useful diagnostic tool in delineating necrotizing vs non-necrotizing soft tissue infections. ${ }^{43}$ It has also been implicated as a predictor of gangrenous cholecystitis, ${ }^{10,44}$ ischemic bowel in small bowel obstruction, ${ }^{45}$ and perforated colonic pathology in elderly patients undergoing emergency general surgery operations. ${ }^{10,40}$

\section{Imaging}

Imaging is an important adjunct to the diagnosis of appendicitis, but it is not always mandatory and the diagnostic accuracy is not $100 \%$. $^{7}$ Imaging modalities include plain radiography, ultrasound (US), CT, and MRI. Most authors advocate for selective imaging when the diagnosis is uncertain given the risks, benefits, costs, and time delay to surgery associated with imaging. ${ }^{9,46-48}$ Staged imaging protocols have also been recommended to minimize the risks of contrast and radiation to pediatric patients. , $^{9,46-48}$

Plain radiography has limited benefit in diagnosing appendicitis and plays a minimal role in distinguishing nonperforated vs perforated appendicitis. ${ }^{9}$ Findings associated with appendicitis include lumbar scoliosis and obliteration of the psoas shadow. ${ }^{9}$ An appendicolith, which is associated with but not diagnostic of perforated appendicitis, is observed on $10 \%-20 \%$ of films in patients with appendicitis. ${ }^{9,24}$ Plain radiography may be more useful in other disease processes when suspicion for appendicitis is low. ${ }^{9,12}$

US is a favored imaging modality given its low risk profile. It is recommended as the first imaging modality in patients with atypical symptoms and often as the first imaging study in staged imaging protocols. ${ }^{9,46-49}$ US provides the benefits of being performed at the bedside, is noninvasive, does not require contrast, and has no radiation exposure. ${ }^{5,9,12}$ It has the drawbacks of being operator dependent, requires patient cooperation which can be challenging in young children, lacks sensitivity in early appendicitis, and is less accurate in obese patients. ${ }^{5,9,12}$ A normal appendix must be visualized to rule out appendicitis. ${ }^{9}$ Sensitivity is usually greater than $80 \%$, and specificity is greater than $90 \%$ for non-perforated appendicitis. ${ }^{5,9}$ In perforated appendicitis, this decreases to a sensitivity of $35 \%$ and specificity of $98 \%{ }^{25}$ 
CT is often thought to be more accurate than US in perforated appendicitis. ${ }^{9,12,46,47}$ It is a second choice imaging modality when US is inconclusive for acute appendicitis, ${ }^{9,47-49}$ but a first choice imaging modality in perforated appendicitis. ${ }^{46}$ It is not operator dependent, but it may require sedation and has the risk of ionizing radiation, possibly resulting in future malignancy. $5,9,12,46$ Sensitivity and specificity approach 95\% for acute appendicitis, ${ }^{5,9,12,50}$ but this is lower in perforated appendicitis. ${ }^{9,51}$ When 200 CT scans of perforated appendicitis were reviewed by junior and senior surgical residents, two staff interventional radiologists, and four attending pediatric surgeons, accuracy was $72 \%$ with sensitivity of $62 \%$ and specificity of $81 \% .{ }^{51}$ Findings on $\mathrm{CT}$ associated with perforated appendicitis include the presence of an abscess, appendicolith, and extraluminal air. ${ }^{5}$

MRI is advocated by some for its benefits of being extremely accurate and lack of radiation., ${ }^{9,52-57}$ Although an older study found MRI comparable to US in diagnosing perforated appendicitis, ${ }^{58}$ newer studies promote its accuracy, ${ }^{53-55}$ including the ability to differentiate acute from perforated appendicitis. ${ }^{52}$ Several of these studies have also shown excellent accuracy without using contrast. ${ }^{53,55}$ Critics mention factors such as availability, time, and cost making MRI impractical for widespread application in pediatrics. ${ }^{9,56}$ Yet, recent advances in MRI techniques such as open MRI negate the need for sedation and make it much more accessible.

\section{Management}

The optimal treatment for perforated appendicitis remains controversial and complex. 4,6,18,19,22,23,32,59-61 Although most authors concur on the importance of fluid resuscitation and antibiotics, one study in 1980 reported minimal morbidity with close observation and no administration of antibiotics for pediatric patients who present with greater than 5 days of symptoms with a palpable mass and no generalized peritonitis. ${ }^{59}$ Current standard of care and practice guidelines advocate for the early initiation of antibiotics in treatment algorithms. ${ }^{32,62-65}$ After initiation of antibiotics, treatment options diverge into operative management or non-operative management with or without interval appendectomy. Although there continues to be extensive debate regarding the merits of each treatment option, this review will highlight the indications for each option and propose an algorithm to assist with treatment decisions.

\section{Antibiotic regimen}

A multitude of antibiotic regimens exist from the classic triple antibiotic regimen to effective dual and single agent regimens. Triple antibiotic therapy consists of ampicillin, gentamicin, and clindamycin or metronidazole for usually 10-14 days. ${ }^{4,9,15,66-71}$ This regimen was found to be effective, relatively inexpensive, and have minimal morbidity. ${ }^{15,66}$ Due to concerns for cost, ${ }^{15,66}$ complexity of multiple daily doses, ${ }^{15}$ and need for blood to monitor gentamicin nephrotoxicity, ${ }^{15}$ alternative regimens were pursued. The most commonly described alternative regimen involves once daily dosing of ceftriaxone and metronidazole., ${ }^{4,15,63,65,68,71-73}$ This regimen was found to be superior to triple antibiotic therapy in terms of lower postoperative temperatures, decreased postoperative abscess rate, shorter LOS, and reduced costs. ${ }^{15,65,68}$ Alternative dual antibiotic regimens ${ }^{65,67,73}$ and single antibiotic regimens ${ }^{4,15,65,66,73}$ have also been well described with good efficacy and similar benefits of shorter LOS and reduced cost. ${ }^{65,71,73}$

\section{Non-operative management: early studies}

The non-operative approach to appendicitis was advocated in as early as 1901 by Ochsner. ${ }^{59,74}$ It took many decades before similar literature was published for pediatric patients with perforated appendicitis..$^{59,69,75,76}$ In most of these studies, perforation was described as an appendiceal mass..$^{59,75,76}$ Janik et al published one of the first articles where 37 pediatric patients presenting with more than 5 days of symptoms, leukocytosis, and a focal appendiceal mass without signs of peritonitis received closer observation in the hospital and no antibiotics. Eighty-one percent of the patients ( 31 children) clinically improved in 5-22 days. The remaining $19 \%$ had recurrence or worsening of symptoms requiring abscess drainage in $2-10$ days. There were no fatalities and only one child had recurrent symptoms prior to receiving interval appendectomy. They concluded nonoperative management with close observation was safe in selected patients and that interval appendectomy can be performed as late as 20 weeks after symptom resolution. ${ }^{59}$ Powers et al also advocated for the safety of non-operative management in perforated appendicitis where patients were treated with triple antibiotic therapy and closely followed until interval appendectomy. ${ }^{69}$ Appendectomy was recommended if there was no clinical improvement in 12-24 hours or if there was recurrence of symptoms, specifically fever or abdominal pain. ${ }^{69} \mathrm{~A}$ similar success rate of greater than $80 \%$ for non-operative management was observed by Skoubo-Kristensen and Hvid. ${ }^{75}$ Over 10 years, 193 adult and pediatric patients were treated. In 23 patients (12\%) operation was needed in the initial period, and of the 170 patients successfully treated, 12 recurred $(7.1 \%)$. The 
patients who underwent interval appendectomy had a low rate of operative complications (3.4\%) for small bowel obstruction, wound infections, and abscess. ${ }^{75}$ Bagi and Dueholm also noted successful treatment of 40 adult and pediatric patients with an appendiceal mass with antibiotics and percutaneous drainage if an abscess was visualized. ${ }^{76}$ The main conclusions of these early publications focused on safety, efficacy, and viability of non-operative management in perforated appendicitis.

\section{Non-operative management: benefits}

Success of non-operative management has been well documented in numerous studies. ${ }^{61,70,77-93}$ Some studies specify the presence of a mass or discrete abscess in the description of perforated appendicitis and non-operative management. ${ }^{77-88}$ Successful treatment has been seen with drainage ${ }^{76,81,87,94-96}$ and no drainage ${ }^{77,88,97}$ of abscesses. Other studies highlight the success of non-operative management and do not make a distinction regarding the presence of mass or discrete abscess. ${ }^{61,70,89-93}$ Documented benefits include decreased morbidity, ${ }^{68,70,80,81,86,89,90,96,98}$ shorter LOS, ${ }^{70,84,99}$ lower costs, ${ }^{71,84,89}$ improved quality of life, ${ }^{71}$ and fewer days off. ${ }^{71}$

Patient morbidity has many manifestations and can range in severity from mild to severe. The most commonly noted source of morbidity with early appendectomy is increased postoperative complications..$^{70,80,86,90,96,98,100}$ These may be infectious in nature such as wound infections, ${ }^{70,98,100}$ abscess development, ${ }^{70,90,98,100}$ and unspecified infectious complications. ${ }^{86,96,98}$ Other types of complications may include bowel obstruction, ${ }^{98,100}$ reoperation, ${ }^{98,100}$ and readmission. ${ }^{6,30}$ Mortality is very rare in pediatric perforated appendicitis. ${ }^{6}$ Multiple studies noted shorter LOS, another manifestation of decreased morbidity, with non-operative management. ${ }^{70,84,99}$ Shorter LOS likely contributed to the decreased costs associated with non-operative management. ${ }^{71,84,89}$ Additional cost saving comes from the complete avoidance of an operation when patients are treated with antibiotics alone. ${ }^{71}$

\section{Non-operative management: drainage controversy}

Within non-operative management, the role of abscess drainage remains controversial. Described as early as 1986, Bagi and Dueholm noted the benefits of percutaneous drainage. ${ }^{76}$ Of the 31 patients noted to have an abscess on US, 17 underwent percutaneous drainage. Sixteen (94\%) of the percutaneously drained patients had symptom resolution with few complications and minimal late sequelae. ${ }^{76}$ St Peter et al randomized 40 pediatric patients to either early appendectomy $(n=20)$ or non-operative management with abscess drainage $(n=20) .{ }^{95}$ The non-operative cohort had eleven drains placed; three patients had abscess aspiration but no drain placement, and six had no drain as the abscess was felt to be inaccessible by interventional radiology. ${ }^{95}$ The non-operative group had a significantly faster return to oral intake and fewer health care visits. ${ }^{95}$ One of the largest studies to date regarding abscess drainage is by Luo et al. ${ }^{87}$ While most studies have cohorts of less than 40 patients undergoing drainage, ${ }^{76,77,81,94-96}$ Luo's study had 1,225 pediatric patients where 150 (12.2\%) underwent drainage and $1,075(87.8 \%)$ received only antibiotics and no drainage. ${ }^{87}$ Although the patients with drainage had a longer LOS, significantly lower recurrence, decreased rate of interval appendectomy, and fewer complications following interval appendectomy were observed. ${ }^{87}$ Older patients 13-18 years old had significantly lower need for interval appendectomy compared to two younger cohorts of 7-12 years old and 6 years old or younger. ${ }^{87}$ Multiple additional studies have supported the role of abscess drainage ${ }^{81,94,96}$ with benefits of symptomatic improvement ${ }^{81,94}$ and decreased postoperative complications. ${ }^{96}$

Although multiple studies are overall in favor of drainage, ${ }^{76,81,87,94-96}$ downsides such as technical failure, ${ }^{81,94}$ increased LOS, ${ }^{87}$ readmission, ${ }^{81}$ increased imaging, ${ }^{95,97}$ and increased number of physician visits ${ }^{95}$ are described in these studies. Hoffmann et al advocated that treatment without drainage was safe and effective. ${ }^{77}$ They followed 37 patients where 28 were treated with observation alone and 19 underwent immediate operation. The observation group was admitted for a median of 10 days (range 1-36 days) and had no in-hospital complications. After discharge, one patient developed recurrent appendicitis and another patient developed a recurrent abscess. In contrast, the immediate operation group had a slightly shorter median hospital stay (8 days, range 4-36 days) but significantly more complications $(n=10) .{ }^{77}$ Keckler et al raised numerous concerns with percutaneous drainage including procedural complications, persistent symptoms, recurrent abscess, multiple CT scans, numerous office visits, and increased financial burden. ${ }^{88}$ One of the largest retrospective reviews critical of drain placement was by Gasior et al. ${ }^{97}$ Two-hundred seventeen pediatric patients with perforated appendicitis and an abscess greater than $5 \mathrm{~cm}^{2}$ were included; 160 had a drain placed and 57 either had aspiration with no drain placement or no procedure at all. The patients with drains had larger abscesses, more CT scans, and more total health care visits. 
After correcting for abscess size, the patients with drains still received more $\mathrm{CT}$ scans and total health care visits. There was no difference in total number of antibiotic days, complications, or recurrence rates. ${ }^{97}$ They proposed that abscesses under $20 \mathrm{~cm}^{2}$ could be treated with antibiotics alone, but that additional randomized studies are needed to validate this threshold..$^{97}$

\section{Non-operative management: role for interval appendectomy}

The necessity of interval appendectomy has recently been questioned by several authors. ${ }^{61,83,84,92,99,101-106}$ Early studies of non-operative management routinely included interval appendectomy, ${ }^{59,69,75,89}$ and this trend has continued for several decades. ${ }^{49,64,78,79,81,82,86,88,90,95,96,100,107,108}$ Proponents of interval appendectomy cite low morbidity ${ }^{70,85,91,109}$ and decreased risk of appendicitis recurrence. ${ }^{85,109,110}$ An additional benefit is the removal of undiagnosed pathology such as carcinoid, appendiceal duplication, Meckel's diverticulum, and malignancy. ${ }^{6,85,100,109}$ The inflammatory reaction in perforated appendicitis was thought by many surgeons to lead to appendiceal fibrosis and the obliteration of the appendiceal lumen, ultimately preventing the development of future episodes of appendicitis. ${ }^{109}$ This theory was disproven on examination of interval appendectomy specimens. ${ }^{91,100,109,111}$ The rate of obliterated lumens ranged from $0 \%$ to $16 \%$, demonstrating patients remain at risk for recurrent appendicitis. ${ }^{91,100,109}$ St. Peter and Snyder noted a $1 \%-3 \%$ annual risk of recurrent appendicitis and that interval appendectomy may be indicated when a child has $60-80$ years of life expectancy. ${ }^{100}$ Recent practice guidelines for perforated appendicitis echo this sentiment and advocate for interval appendectomy given the risk of recurrence remains $8 \%-15 \% .^{64,71}$

Critics of interval appendectomy question its necessity in all patients ${ }^{61,84,101,103,104,106}$ and some propose a more selective approach. ${ }^{83,99}$ The low risk of appendicitis recurrence is a frequent rationale against routine interval appendectomy. ${ }^{101,102,104}$ Hall et al found that $80 \%$ of patients do not need an interval appendectomy; five interval appendectomies needed to be performed for one patient to benefit from avoiding appendicitis recurrence. ${ }^{101}$ They noted that interval appendectomy would treat less than $1 \%$ of missed carcinoid diagnoses and there remains a small, but real risk of complication at $3 \%{ }^{101}$ Other critics observed a higher risk of complications, up to one-third of patients undergoing interval appendectomy. ${ }^{92,102,112}$ Increased costs, ${ }^{84,102,105,112}$ longer LOS, ${ }^{104}$ and difficulty with repeat operation ${ }^{106}$ are other arguments against performing interval appendectomy.

\section{Predicting failure of non-operative management}

Appropriately selecting patients for non-operative management is essential to its success. A substantial number of studies have commented on various factors that are predictive of success and/or failure of non-operative management. ${ }^{33,71,83,89,92-94,96,99,100,103,107,109,110,113-116}$ The presence of an appendicolith has been implicated in increased risk of recurrent appendicitis and failure of non-operative management. ${ }^{33,71,100,103,109,110,115}$ Although this is the most commonly cited reason for failure of non-operative management, Talishinskiy et al found appendicolith was not predictive of non-operative failure in their retrospective review of 64 cases of pediatric perforated appendicitis. ${ }^{93}$ Zhang et al found that most appendicoliths resolve and that the presence of a persistent appendicolith was more predictive of failing non-operative management. ${ }^{83}$ Nazarey et al reviewed 105 pediatric perforated appendicitis cases managed non-operatively and found the combination of an appendicolith plus leukocytosis greater than 15,000 white blood cells (WBC) per microliter was associated with treatment failure. ${ }^{92}$ Bandemia has been associated with non-operative failure in several studies, ${ }^{93,99,100,107,116}$ particularly when the percentage of bands exceeds 15\%. ${ }^{93,100,107}$ Extensive disease on imaging has also been associated with failure of non-operative management, but several different definitions of extensive disease have been utilized. ${ }^{94,96,99,100,113,114,116} \mathrm{CT}$ with findings outside the right lower quadrant ${ }^{100,113,116}$ and large or poorly defined abscess ${ }^{94,96,114}$ are common definitions. Free peritoneal fluid on imaging is another definition used as well. ${ }^{99}$ The presence of a bowel obstruction has also been linked with failure of non-operative management. ${ }^{89,93,99}$ Clinical definitions of a bowel obstruction include symptoms being present for greater than 72 hours ${ }^{89}$ or the need for a nasogastric tube within the first day or two of admission. ${ }^{99}$ The literature is mixed on other factors such as symptom duration ${ }^{92,93,114}$ and the presence or absence of an abscess ${ }^{93,96,115}$ at predicting who will fail non-operative management. Whyte et al looked at 58 patients who underwent non-operative management of CT-proven perforated appendicitis and found that fever after 24 hours of treatment was associated with increased risk of failure. ${ }^{116}$ The importance of continued evaluation and assessment of the patient's response to non-operative management cannot be emphasized enough. If patients 
fail to improve with conservative measures, appendectomy should be pursued. ${ }^{4,116}$

\section{Operative management: early appendectomy}

Many surgeons and studies advocate for early appendectomy in the setting of perforated appendicitis. ${ }^{4,6,15,22,23,32,64,71,93,95,100,103,108,112,117-120}$ The best quality of evidence is found in two separate randomized trials. ${ }^{6,95} \mathrm{St}$ Peter et al performed a pilot study with 40 patients aged 7-18 years with a diagnosis of perforated appendicitis with an abscess that were randomized to early appendectomy $(n=20)$ and non-operative management that consisted of intravenous antibiotics, percutaneous drainage when feasible, and interval appendectomy $(\mathrm{n}=20) .{ }^{95}$ Both cohorts were similarly matched in patient characteristics such as age, weight, body mass index (BMI), WBC, maximum temperature, and maximum axial area of abscess in $\mathrm{cm} .^{2}$ The early appendectomy group trended toward longer operating times, but this was not significant. The early appendectomy group did have fewer health care visits and less CT scans, but no difference in total charges. Aside from faster time to oral intake, the non-operative group did not demonstrate improved outcomes compared to the early appendectomy group..$^{95}$ Blakely et al performed a randomized trial of 131 patients less than 18 years old with a diagnosis of perforated appendicitis without a mass or well-formed abscess. ${ }^{6}$ Sixty-four patients were randomized to early appendectomy within 24 hours of admission, and 67 were randomized to non-operative management with antibiotics and interval appendectomy. The cohorts were similarly matched for age, sex, race, duration of symptoms, admission WBC, CT scan completed at initial assessment, presence of an intra-abdominal abscess, and intensive care unit admission. The only significant difference between the groups was a higher emergency department temperature in the interval appendectomy group $\left(38.4^{\circ} \mathrm{C}\right.$ vs $\left.38.0^{\circ} \mathrm{C}\right)$. The early appendectomy group experienced significantly fewer adverse events and decreased time away from normal activities. $^{6}$

Multiple studies have demonstrated decreased morbidity in early appendectomy compared to non-operative management with or without interval appendectomy. $6,22,23,93,100,108,118-120$ Decreased complications and adverse events such as intraabdominal abscess, small bowel obstruction, need for total parenteral nutrition, and central line related adverse events have been seen with early appendectomy. ${ }^{6,22,93,118}$ Decreased number of procedures ${ }^{22,23,100}$ and fewer imaging studies ${ }^{22,23,93,95}$ are other benefits. Health care utilization is less with early appendectomy with decreased LOS, $22,93,100,108,119$ fewer days of intravenous antibiotics, ${ }^{22,119}$ less doctor visits, ${ }^{23,95,119}$ and decreased subsequent hospital admissions. ${ }^{22,23,118,119}$ Patientcentered outcomes such as decreased recovery time, ${ }^{6,108}$ improved patient quality of life at 3 months, ${ }^{120}$ and decreased parental stress at 3 months ${ }^{120}$ have also been documented.

Proponents of early appendectomy also point to the associated financial benefits..$^{23,32,64,100,108,112,118,119}$ Some of these financial benefits stem from increased health care utilization seen with interval appendectomy in terms of increased LOS, increased readmissions, and increased complications. ${ }^{112,119,121}$ In an analysis of Blakely et al's randomized controlled trial, Myers et al examined the hospital costs of both cohorts. ${ }^{112}$ Early appendectomy was associated with lower costs due to fewer complications and a smaller number of unplanned readmissions. Patients who experienced adverse events in the trial had double the costs of those who did not have an adverse event. ${ }^{112}$

\section{Treatment algorithm}

Although the diagnosis and management of perforated appendicitis remains complex and controversial, guidelines exist and have been demonstrated to both improve patient outcomes and decrease resource utilization. ${ }^{31,32,62-64}$ Although clinician experience is the best tool in making an accurate diagnosis, ${ }^{5,21,36}$ laboratory studies and selective imaging should be utilized to assist in diagnosis. After a diagnosis of perforated appendicitis is made, all patients should be placed nil per os and started on appropriate broad-spectrum IV antibiotics.

Patients with hemodynamic instability and/or diffuse peritonitis should proceed to appendectomy after aggressive resuscitation. Patients with an early presentation and symptoms of less than 5-7 days should also proceed to the operating room. Patients who are hemodynamically stable, without diffuse peritonitis, and have a delayed presentation of 5-7 days or greater are candidates for non-operative management. If an abscess is present and amenable to drainage, this should be pursued. It is important to be mindful of which patients are at increased risk of failing non-operative management. Close observation, evaluation, and assessment should continue. If the patient fails to improve within 24-48 hours, non-operative management should be abandoned and appendectomy pursued.

In patients managed with appendectomy or with nonoperative management, antibiotics should be continued while the patient remains admitted. Although a 5-day course of IV antibiotics is recommended, the duration should be based on 
clinical criteria. ${ }^{65}$ Intravenous antibiotics should be continued until patients are afebrile for 24 hours, are tolerating a diet, and their pain remains well-controlled. At this point, patients may be discharged. The role of oral antibiotics for an outpatient after discharge is debated, but current recommendations are for a total duration of 7 days, particularly if the patient is discharged prior to 5 days of IV antibiotics. ${ }^{65}$ Patients managed non-operatively should be followed closely in the outpatient setting, be counseled on the signs and symptoms of recurrent appendicitis, and advised to return promptly should such symptoms arise. After completing non-operative management, patients should undergo interval appendectomy.

\section{Conclusion}

Although diagnosis of perforated appendicitis is challenging, it remains important in guiding management of patients. No single symptom or sign is predictive of acute appendicitis, but patients at increased risk include socially and economically disadvantaged, those without private health insurance, minorities, and younger patients. Diagnostic clues include longer duration of symptoms, diffuse peritoneal signs, elevated fevers, markedly elevated leukocytosis, bandemia, elevated CRP, hyponatremia, and ESR greater than $25 \mathrm{~mm} / \mathrm{h}$. Imaging, especially US and CT, are useful adjuncts but not always necessary. The best diagnostic indicator remains physician experience and expertise as pediatric surgeons have greater than $90 \%$ accuracy in distinguishing non-appendicitis, acute appendicitis, and perforated appendicitis.

Management options include non-operative management with antibiotics and no interval appendectomy, nonoperative management with interval appendectomy, and early appendectomy during index hospitalization. Non-operative management has been demonstrated to be safe and efficacious in appropriately selected patients. Risk factors for failing non-operative management include the presence of an appendicolith, leukocytosis greater than 15,000 WBC per microliter, increased bands, and CT evidence of extensive disease. Critics note increased imaging, number of health care visits, cost, and complications are associated with nonoperative management. There is a paucity of randomized trials. Pooled results from two randomized trials comparing non-operative management with interval appendectomy found early appendectomy was associated with decreased time away from normal activities, fewer adverse events, lower costs, fewer health care visits, and a smaller number of imaging studies. Patients remain on intravenous antibiotics until they are afebrile with stable vital signs, well-controlled pain, and tolerating a regular diet. There continues to be debate regarding the optimal duration of antibiotics once a patient is discharged to home.

Following treatment guidelines and an algorithm simplifies complex management decisions and improves patient outcomes. Perforated appendicitis remains challenging to diagnose and complex to manage. Most data are retrospective and from single institution studies. More multi-institutional, randomized trials are needed to further evaluate the safety, efficacy, and indications of the various treatment options.

\section{Disclosure}

The authors report no conflicts of interest in this work.

\section{References}

1. Curran TJ, Muenchow SK. The treatment of complicated appendicitis in children using peritoneal drainage: Results from a public hospital. J Pediatr Surg. 1993;28(2):204-208.

2. Sivit CJ, Siegel MJ, Applegate KE, Newman KD. When Appendicitis Is Suspected in Children. Radiographics. 2001;21(1):247-262; questionnaire 288-294.

3. Guthery SL, Hutchings C, Michael Dean J, Hoff C. National estimates of hospital utilization by children with gastrointestinal disorders: analysis of the 1997 kids' inpatient database. $J$ Pediatr. 2004;144(5):589-594.

4. Morrow SE, Newman KD. Current management of appendicitis. Semin Pediatr Surg. 2007;16(1):34-40.

5. Gosain A, Williams RF, Blakely ML. Distinguishing acute from ruptured appendicitis preoperatively in the pediatric patient. Adv Surg. 2010;44(1):73-85.

6. Blakely ML, Williams R, Dassinger MS, et al. Early vs interval appendectomy for children with perforated appendicitis. Arch Surg. 2011;146(6):660-665.

7. Svensson J, Hall N, Eaton S, Pierro A, Wester T. A review of conservative treatment of acute appendicitis. European Journal of Pediatric Surgery. 2012;22(03):185-194.

8. Svensson JF, Patkova B, Almström M, et al. Nonoperative treatment with antibiotics versus surgery for acute nonperforated appendicitis in children: a pilot randomized controlled trial. Ann Surg. 2015;261(1):67-71.

9. Ashcraft KW, Holcomb GW, Murphy JP, Ostlie DJ, editors. Ashcraft's Pediatric Surgery. 6th ed. London; New York: Saunders/Elsevier; 2014.

10. Pham X-BD, Sullins VF, Kim DY, et al. Factors predictive of complicated appendicitis in children. J Surg Res. 2016;206(1):62-66.

11. Addiss DG, Shaffer N, Fowler BS, Tauxe RV. The epidemiology of appendicitis and appendectomy in the United States. Am J Epidemiol. 1990;132(5):910-925.

12. Brunicardi FC, Andersen DK, Billiar TR, Dunn DL, Hunter JG, editors. Schwartz's Principles of Surgery. 10th ed. New York: McGraw-Hill Education; 2014. .

13. Abeş M, Petik B, Kazil S. Nonoperative treatment of acute appendicitis in children. J Pediatr Surg. 2007;42(8):1439-1442.

14. Andersson RE. The natural history and traditional management of appendicitis revisited: spontaneous resolution and predominance of prehospital perforations imply that a correct diagnosis is more important than an early diagnosis. World J Surg. 2007;31(1):86-92.

15. Holcomb G, St Peter S. Current management of complicated appendicitis in children. European Journal of Pediatric Surgery. 2012;22(03):207-212.

16. Ponsky TA, Hafi M, Heiss K, Dinsmore J, Newman KD, Gilbert J. Interobserver variation in the assessment of appendiceal perforation. Journal of Laparoendoscopic \& Advanced Surgical Techniques. 2009;19(s1):s15-s18. 
17. St. Peter SD, Sharp SW, Holcomb GW, Ostlie DJ. An evidence-based definition for perforated appendicitis derived from a prospective randomized trial. J Pediatr Surg. 2008;43(12):2242-2245.

18. Newman K, Ponsky T, Kittle K, et al. Appendicitis 2000: variability in practice, outcomes, and resource utilization at thirty pediatric hospitals. J Pediatr Surg. 2003;38(3):372-379.

19. Ponsky TAet al. Hospital- and patient-level characteristics and the risk of appendiceal rupture and negative appendectomy in children. JAMA. 2004;292(16):1977-1982.

20. Brender JD, Marcuse EK, Koepsell TD, Hatch EI. Childhood appendicitis: factors associated with perforation. Pediatrics. 1985;76(2):301-306.

21. Williams RF, Blakely ML, Fischer PE, et al. Diagnosing ruptured appendicitis preoperatively in pediatric patients. $J$ Am Coll Surg. 2009;208(5):819-825.

22. Bonadio W, Rebillot K, Ukwuoma O, Saracino C, Iskhakov A. Management of Pediatric Perforated Appendicitis: Comparing Outcomes Using Early Appendectomy Versus Solely Medical Management. Pediatr Infect Dis J. 2017;36(10):937-941.

23. Church JT, Klein EJ, Carr BD, Bruch SW. Early appendectomy reduces costs in children with perforated appendicitis. J Surg Res. 2017;220:119-124.

24. Nance ML, Adamson WT, Hedrick HL. Appendicitis in the young child: A continuing diagnostic challenge. Pediatr Emerg Care. 2000;16(3):160-162.

25. Peng Y-S, Lee H-C, Yeung C-Y, Sheu J-C, Wang N-L, Tsai Y-H. Clinical criteria for diagnosing perforated appendix in pediatric patients. Pediatr Emerg Care. 2006;22(7):475-479.

26. Nelson DS, Bateman B, Bolte RG. Appendiceal perforation in children diagnosed in a pediatric emergency department. Pediatr Emerg Care. 2000;16(4):233-237.

27. Barrett ML, Hines AL, Andrews RM. Trends in Rates of Perforated Appendix, 2001-2010: Statistical Brief \#159. Healthcare Cost and Utilization Project (HCUP) Statistical Briefs. Rockville (MD): Agency for Healthcare Research and Quality (US); 2006. http://www.ncbi.nlm. nih.gov/books/NBK169006/. Accessed May 27, 2018.

28. Sarda S, Short HL, Hockenberry JM, Mccarthy I, Raval MV. Regional variation in rates of pediatric perforated appendicitis. J Pediatr Surg. 2017;52(9):1488-1491.

29. Bickell NA, Aufses AH, Rojas M, Bodian C. How time affects the risk of rupture in appendicitis. J Am Coll Surg. 2006;202(3):401-406.

30. Siddique K, Baruah P, Bhandari S, Mirza S, Harinath G. Diagnostic accuracy of white cell count and C-reactive protein for assessing the severity of paediatric appendicitis. JRSM Short Rep. 2011;2(7):59-6.

31. Stringel G. Appendicitis in children: A systematic approach for a low incidence of complications. The American Journal of Surgery. 1987;154(6):631-635.

32. Willis ZI, Duggan EM, Bucher BT, et al. Effect of a Clinical Practice Guideline for Pediatric Complicated Appendicitis. JAMA Surg. 2016;151(5):e160194.

33. Minneci PC, Sulkowski JP, Nacion KM, et al. Feasibility of a nonoperative management strategy for uncomplicated acute appendicitis in children. J Am Coll Surg. 2014;219(2):272-279.

34. Rothrock SG, Skeoch G, Rush JJ, Johnson NE. Clinical features of misdiagnosed appendicitis in children. Ann Emerg Med. 1991;20(1):45-50.

35. Chang Y-J, Chao H-C, Kong M-S, Hsia S-H, Yan D-C. Misdiagnosed acute appendicitis in children in the emergency department. Chang Gung Med J. 2010;33(5):551-557.

36. Kosloske AM, Love CL, Rohrer JE, Goldthorn JF, Lacey SR. The diagnosis of appendicitis in children: outcomes of a strategy based on pediatric surgical evaluation. Pediatrics. 2004;113(1):29-34.

37. Lin C-J, Chen J-D, Tiu C-M, et al. Can ruptured appendicitis be detected preoperatively in the ED? Am J Emerg Med. 2005;23(1):60-66.

38. Beltrán MA, Almonacid J, Vicencio A, Gutiérrez J, Cruces KS, Cumsille MA. Predictive value of white blood cell count and C-reactive protein in children with appendicitis. J Pediatr Surg. 2007;42(7):1208-1214.
39. Kim DY, Nassiri N, de Virgilio C, et al. Association Between Hyponatremia and Complicated Appendicitis. JAMA Surg. 2015;150(9): 911-912.

40. Käser SA, Furler R, Evequoz DC, Maurer CA. Hyponatremia is a specific marker of perforation in sigmoid diverticulitis or appendicitis in patients older than 50 years. Gastroenterol Res Pract. 2013;2013(11):462891.

41. Yaghoubian A, de Virgilio C, Dauphine C, Lewis RJ, Lin M. Use of admission serum lactate and sodium levels to predict mortality in necrotizing soft-tissue infections. Arch Surg. 2007;142(9):840-846.

42. Wall DB, de Virgilio C, Black S, Klein SR. Objective criteria may assist in distinguishing necrotizing fasciitis from nonnecrotizing soft tissue infection. The American Journal of Surgery. 2000;179(1):17-20.

43. Wong C-H, Khin L-W, Heng K-S, Tan K-C, Low C-O. The LRINEC (Laboratory Risk Indicator for Necrotizing Fasciitis) score: A tool for distinguishing necrotizing fasciitis from other soft tissue infections*. Crit Care Med. 2004;32(7):1535-1541.

44. Falor AE, Zobel M, Kaji A, Neville A, de Virgilio C. Admission variables predictive of gangrenous cholecystitis. Am Surg. 2012;78(10):1075-1078.

45. O'Leary MP, Neville AL, Keeley JA, Kim DY, de Virgilio C, Plurad DS. Predictors of Ischemic Bowel in Patients with Small Bowel Obstruction. Am Surg. 2016;82(10):992-994.

46. Russell WS, Schuh AM, Hill JG, et al. Clinical practice guidelines for pediatric appendicitis evaluation can decrease computed tomography utilization while maintaining diagnostic accuracy. Pediatr Emerg Care. 2013;29(5):568-573.

47. Garcia Peña BM, Cook EF, Mandl KD. Selective Imaging Strategies for the Diagnosis of Appendicitis in Children. Pediatrics. 2004;113(1):24-28.

48. Garcia Pena BM, Taylor GA, Fishman SJ, Mandl KD. Costs and effectiveness of ultrasonography and limited computed tomography for diagnosing appendicitis in children. Pediatrics. 2000;106(4):672-676.

49. Hansen LW, Dolgin SE. Trends in the Diagnosis and Management of Pediatric Appendicitis. Pediatr Rev. 2016;37(2):52-58.

50. Peña BMG, Taylor GA, Lund DP, Mandl KD. Effect of computed tomography on patient management and costs in children with suspected appendicitis. Pediatrics. 1999;104(3):440-446.

51. Fraser JD, Aguayo P, Sharp SW, et al. Accuracy of computed tomography in predicting appendiceal perforation. J Pediatr Surg. 2010;45(1):231-235.

52. Rosenbaum DG, Askin G, Beneck DM, Kovanlikaya A. Differentiating perforated from non-perforated appendicitis on contrast-enhanced magnetic resonance imaging. Pediatr Radiol. 2017;47(11):1483-1490.

53. Martin JF, Mathison DJ, Mullan PC, Otero HJ. Secondary imaging for suspected appendicitis after equivocal ultrasound: time to disposition of MRI compared to CT. Emerg Radiol. 2018;25(2):161-168.

54. Dibble EH, Swenson DW, Cartagena C, Baird GL, Herliczek TW. Effectiveness of a Staged US and Unenhanced MR Imaging Algorithm in the Diagnosis of Pediatric Appendicitis. Radiology. 2018;286(3):1022-1029.

55. Kim JR, Suh CH, Yoon HM, et al. Performance of MRI for suspected appendicitis in pediatric patients and negative appendectomy rate: A systematic review and meta-analysis. Journal of Magnetic Resonance Imaging. 2018;47(3):767-778.

56. Schulz T, Bennek J, Schneider JP, et al. MRI-guided pediatric interventions. Rofo. 2003;175(12):1673-1681.

57. Schulz T, Tröbs RB, Schneider JP, et al. Pediatric MR-guided interventions. Eur J Radiol. 2005;53(1):57-66.

58. Leeuwenburgh MM, Wiezer MJ, Wiarda BM, et al; OPTIMAP study group. Accuracy of MRI compared with ultrasound imaging and selective use of CT to discriminate simple from perforated appendicitis. $\mathrm{Br}$ J Surg. 2014;101(1):e147-e155.

59. Janik JS, Ein SH, Shandling B, Simpson JS, Stephens CA. Nonsurgical management of appendiceal mass in late presenting children. J Pediatr Surg. 1980;15(4):574-576. 
60. Chen C, Botelho C, Cooper A, Hibberd P, Parsons SK. Current practice patterns in the treatment of perforated appendicitis in children. $J \mathrm{Am}$ Coll Surg. 2003;196(2):212-221.

61. López JJ, Deans KJ, Minneci PC. Nonoperative management of appendicitis in children. Curr Opin Pediatr. 2017;29(3):358-362.

62. Robinson JR, Avritscher EBC, Gay JC, et al. Measuring the Value of a Clinical Practice Guideline for Children With Perforated Appendicitis. Ann Surg. 2017;266(1):195-200.

63. Knott EM, Gasior AC, Ostlie DJ, Holcomb GW, St. Peter SD. Decreased resource utilization since initiation of institutional clinical pathway for care of children with perforated appendicitis. J Pediatr Surg. 2013;48(6):1395-1398.

64. Slusher J, Bates CA, Johnson C, Williams C, Dasgupta R, von Allmen D. Standardization and improvement of care for pediatric patients with perforated appendicitis. J Pediatr Surg. 2014;49(6):1020-1025.

65. Lee SL, Islam S, Cassidy LD, Abdullah F, Arca MJ. Antibiotics and appendicitis in the pediatric population: an American Pediatric Surgical Association Outcomes and Clinical Trials Committee Systematic Review. J Pediatr Surg. 2010;45(11):2181-2185.

66. Fishman SJ, Pelosi L, Klavon SL, O'Rourke EJ. Perforated appendicitis: Prospective outcome analysis for 150 children. J Pediatr Surg. 2000;35(6):923-926.

67. Rodriguez JC, Buckner D, Schoenike S, Gomez-Marin O, Oiticica C, Thompson WR. Comparison of two antibiotic regimens in the treatment of perforated appendicitis in pediatric patients. Int. Journal of Clinical Pharmacology and Therapeutics. 2000;38(10):492-499.

68. St. Peter SD, Little DC, Calkins CM, et al. A simple and more costeffective antibiotic regimen for perforated appendicitis. J Pediatr Surg. 2006;41(5):1020-1024.

69. Powers RJ, Andrassy RJ, Brennan LP, Weitzman JJ. Alternate approach to the management of acute perforating appendicitis in children. Surg Gynecol Obstet. 1981;152(4):473-475.

70. Vane DW, Fernandez N. Role of Interval Appendectomy in the Management of Complicated Appendicitis in Children. World J Surg. 2006;30(1):51-54.

71. Rentea RM, St. Peter SD. Pediatric Appendicitis. Surg Clin North Am. 2017;97(1):93-112.

72. Hurst AL, Olson D, Somme S, et al. Once-Daily Ceftriaxone Plus Metronidazole Versus Ertapenem and/or Cefoxitin for Pediatric Appendicitis. J Pediatric Infect Dis Soc. 2017;6(1):57-64.

73. Guillet-Caruba C, Cheikhelard A, Guillet M, et al. Bacteriologic epidemiology and empirical treatment of pediatric complicated appendicitis. Diagn Microbiol Infect Dis. 2011;69(4):376-381.

74. Ochsner AJ. The cause of diffuse peritonitis complicating appendicitis and its prevention: Chairman's address, delivered before the section on surgery and anatomy, at the fifty-second annual meeting of the A. M. A., at St. Paul, Minn., June 4-7, 1901. J Am Med Assoc. 1901;XXXVI(25):1747-1754.

75. Skoubo-Kristensen E, Hvid I. The appendiceal mass: results of conservative management. Ann Surg. 1982;196(5):584-587.

76. Bagi P, Dueholm S. Nonoperative management of the ultrasonically evaluated appendiceal mass. Surgery. 1987;101(5):602-605.

77. Hoffmann J, Rolff M, Lomborg V, Franzmann M. Ultraconservative management of appendiceal abscess. J R Coll Surg Edinb. 1991;36(1):18-20.

78. Gillick J, Velayudham M, Puri P. Conservative management of appendix mass in children. Br J Surg. 2001;88(11):1539-1542.

79. Guida E, Pederiva F, Grazia MD, et al. Perforated appendix with abscess: Immediate or interval appendectomy? Some examples to explain our choice. Int J Surg Case Rep. 2015;12:15-18.

80. Erdoğan D, Karaman Ibrahim, Narcı A, et al. Comparison of two methods for the management of appendicular mass in children. Pediatr Surg Int. 2005;21(2):81-83.

81. Roach JP, Partrick DA, Bruny JL, Allshouse MJ, Karrer FM, Ziegler MM. Complicated appendicitis in children: a clear role for drainage and delayed appendectomy. Am J Surg. 2007;194(6):769-773.

82. Emil S, Duong S. Antibiotic therapy and interval appendectomy for perforated appendicitis in children: a selective approach. Am Surg. 2007;73(9):917-922.
83. Zhang H-L, Bai Y-Z, Zhou X, Wang W-L. Nonoperative Management of Appendiceal Phlegmon or Abscess with an Appendicolith in Children. Journal of Gastrointestinal Surgery. 2013;17(4):766-770.

84. Fawkner-Corbett D, Jawaid WB, Mcpartland J, Losty PD. Interval appendectomy in children clinical outcomes, financial costs and patient benefits. Pediatr Surg Int. 2014;30(7):743-746.

85. Owen A, Moore O, Marven S, Roberts J. Interval Laparoscopic Appendectomy in Children. Journal of Laparoendoscopic \& Advanced Surgical Techniques. 2006;16(3):308-311.

86. Furuya T, Inoue M, Sugito K, et al. Effectiveness of Interval Appendectomy After Conservative Treatment of Pediatric Ruptured Appendicitis with Abscess. Indian J Surg. 2015;77(S3):1041-1044.

87. Luo C-C, Cheng K-F, Huang C-S, et al. Therapeutic effectiveness of percutaneous drainage and factors for performing an interval appendectomy in pediatric appendiceal abscess. BMC Surg. 2016;16(1):72.

88. Keckler SJ, Tsao K, Sharp SW, Ostlie DJ, Holcomb GW, St. Peter SD. Resource utilization and outcomes from percutaneous drainage and interval appendectomy for perforated appendicitis with abscess. J Pediatr Surg. 2008;43(6):977-980.

89. Bufo AJ, Shah RS, Li MH, et al. Interval appendectomy for perforated appendicitis in children. J Laparoendosc Adv Surg Tech A. 1998;8(4):209-214.

90. Henry MC, Gollin G, Islam S, et al. Matched analysis of nonoperative management vs immediate appendectomy for perforated appendicitis. J Pediatr Surg. 2007;42(1):19-24.

91. Iqbal CW, Knott EM, Mortellaro VE, Fitzgerald KM, Sharp SW, St. Peter SD. Interval appendectomy after perforated appendicitis: what are the operative risks and luminal patency rates? J Surg Res. 2012;177(1):127-130.

92. Nazarey PP, Stylianos S, Velis E, et al. Treatment of suspected acute perforated appendicitis with antibiotics and interval appendectomy. $J$ Pediatr Surg. 2014;49(3):447-450.

93. Talishinskiy T, Limberg J, Ginsburg H, Kuenzler K, Fisher J, Tomita S. Factors associated with failure of nonoperative treatment of complicated appendicitis in children. J Pediatr Surg. 2016;51(7):1174-1176.

94. Mcneeley MF, Vo NJ, Prabhu SJ, Vergnani J, Shaw DW. Percutaneous drainage of intra-abdominal abscess in children with perforated appendicitis. Pediatr Radiol. 2012;42(7):805-812.

95. St. Peter SD, Aguayo P, Fraser JD, et al. Initial laparoscopic appendectomy versus initial nonoperative management and interval appendectomy for perforated appendicitis with abscess: a prospective, randomized trial. J Pediatr Surg. 2010;45(1):236-240.

96. Weber TR, Keller MA, Bower RJ, Spinner G, Vierling K. Is delayed operative treatment worth the trouble with perforated appendicitis is children? Am J Surg. 2003;186(6):685-689.

97. Gasior AC, Marty Knott E, Ostlie DJ, St. Peter SD. To drain or not to drain: an analysis of abscess drains in the treatment of appendicitis with abscess. Pediatr Surg Int. 2013;29(5):455-458.

98. Simillis C, Symeonides P, Shorthouse AJ, Tekkis PP. A metaanalysis comparing conservative treatment versus acute appendectomy for complicated appendicitis (abscess or phlegmon). Surgery. 2010;147(6):818-829.

99. Fawley J, Gollin G. Expanded utilization of nonoperative management for complicated appendicitis in children. Langenbecks Arch Surg. 2013;398(3):463-466.

100. St. Peter SD, Snyder CL. Operative management of appendicitis. Semin Pediatr Surg. 2016;25(4):208-211.

101. Hall NJ, Jones CE, Eaton S, Stanton MP, Burge DM. Is interval appendicectomy justified after successful nonoperative treatment of an appendix mass in children? A systematic review. J Pediatr Surg. 2011;46(4):767-771.

102. Darwazeh G, Cunningham SC, Kowdley GC. A Systematic Review of Perforated Appendicitis and Phlegmon: Interval Appendectomy or Wait-and-See? Am Surg. 2016;82(1):11-15.

103. Gonzalez DO, Deans KJ, Minneci PC. Role of non-operative management in pediatric appendicitis. Semin Pediatr Surg. 2016;25(4):204-207. 
104. Puapong D, Lee SL, Haigh PI, Kaminski A, Liu IL, Applebaum H. Routine interval appendectomy in children is not indicated. J Pediatr Surg. 2007;42(9):1500-1503.

105. Raval MV, Lautz T, Reynolds M, Browne M. Dollars and sense of interval appendectomy in children: a cost analysis. J Pediatr Surg. 2010;45(9):1817-1825.

106. Tanaka Y, Uchida H, Kawashima H, et al. More than one-third of successfully nonoperatively treated patients with complicated appendicitis experienced recurrent appendicitis: Is interval appendectomy necessary? J Pediatr Surg. 2016;51(12):1957-1961.

107. Kogut KA, Blakely ML, Schropp KP, et al. The association of elevated percent bands on admission with failure and complications of interval appendectomy. J Pediatr Surg. 2001;36(1):165-168.

108. Liu ZF, Yu JC, Hsieh HF, Lin CH. Perforated appendicitis: urgency or interval surgery? Zentralbl Chir. 2007;132(6):539-541.

109. Mazziotti MV, Marley EF, Winthrop AL, Fitzgerald PG, Walton M, Langer JC. Histopathologic analysis of interval appendectomy specimens: support for the role of interval appendectomy. J Pediatr Surg. 1997;32(6):806-809.

110. Ein SH, Langer JC, Daneman A. Nonoperative management of pediatric ruptured appendix with inflammatory mass or abscess: presence of an appendicolith predicts recurrent appendicitis. J Pediatr Surg. 2005;40(10):1612-1615.

111. Gahukamble DB, Gahukamble LD. Surgical and pathological basis for interval appendicectomy after resolution of appendicular mass in children. J Pediatr Surg. 2000;35(3):424-427.

112. Myers AL, Williams RF, Giles K, et al. Hospital cost analysis of a prospective, randomized trial of early vs interval appendectomy for perforated appendicitis in children. J Am Coll Surg. 2012;214(4):427-434.
113. Levin T, Whyte C, Borzykowski R, Han B, Blitman N, Harris B. Nonoperative management of perforated appendicitis in children: can CT predict outcome? Pediatr Radiol. 2007;37(3):251-255.

114. Nadler EP, Reblock KK, Vaughan KG, Meza MP, Ford HR, Gaines BA. Predictors of outcome for children with perforated appendicitis initially treated with non-operative management. Surg Infect. 2004;5(4):349-356.

115. Aprahamian CJ, Barnhart DC, Bledsoe SE, Vaid Y, Harmon CM. Failure in the nonoperative management of pediatric ruptured appendicitis: predictors and consequences. J Pediatr Surg. 2007;42(6):934-938.

116. Whyte C, Levin T, Harris BH. Early decisions in perforated appendicitis in children: lessons from a study of nonoperative management. J Pediatr Surg. 2008;43(8):1459-1463.

117. Jordan JS, Kovalcik PJ, Schwab CW. Appendicitis with a palpable mass. Ann Surg. 1981;193(2):227-229.

118. Duggan EM, Marshall AP, Weaver KL, et al. A systematic review and individual patient data meta-analysis of published randomized clinical trials comparing early versus interval appendectomy for children with perforated appendicitis. Pediatr Surg Int. 2016;32(7):649-655.

119. Dennett KV, Tracy S, Fisher S, et al. Treatment of perforated appendicitis in children: what is the cost? J Pediatr Surg. 2012;47(6):1177-1184

120. Schurman JV, Cushing CC, Garey CL, Laituri CA, St Peter SD. Quality of life assessment between laparoscopic appendectomy at presentation and interval appendectomy for perforated appendicitis with abscess: analysis of a prospective randomized trial. J Pediatr Surg. 2011;46(6):1121-1125.

121. Liu JJ, Bellamy GR, Mccormick M. Patient bypass behavior and critical access hospitals: implications for patient retention. J Rural Health 2007;23(1):17-24.
Pediatric Health, Medicine and Therapeutics

\section{Publish your work in this journal}

Pediatric Health, Medicine and Therapeutics is an international, peerreviewed, open access journal publishing original research, reports, editorials, reviews and commentaries. All aspects of health maintenance, preventative measures and disease treatment interventions are addressed within the journal. Practitioners from all disciplines are invited to submit

\section{Dovepress}

their work as well as healthcare researchers and patient support groups. The manuscript management system is completely online and includes a very quick and fair peer-review system. Visit http://www.dovepress.com/ testimonials.php to read real quotes from published authors. 